\title{
USE OF VERY HIGH SPATIAL RESOLUTION IMAGERY FOR MAPPING WOOD ENERGY POTENTIAL FROM TROPICAL MANAGED FOREST STANDS, REUNION ISLAND
}

\author{
H. Bley-Dalouman ${ }^{1,2,3,4, *}$, F. Broust ${ }^{1,2}$, J. Prevost ${ }^{5}$, A. Tran ${ }^{3,4}$ \\ ${ }^{1}$ CIRAD, UPR BioWooEB, F-97743 Saint-Denis, Réunion, France \\ ${ }^{2}$ BioWooEB, Univ Montpellier, CIRAD, Montpellier, France \\ ${ }^{3}$ CIRAD, UMR TETIS, F-97490 Sainte-Clotilde, Réunion, France \\ ${ }^{4}$ TETIS, Univ Montpellier, AgroParisTech, CIRAD, CNRS, INRAE, Montpellier, France \\ ${ }^{5}$ ONF, F-97400 Saint-Denis, Réunion, France \\ (helene.bley-dalouman, francois.broust, annelise.tran)@ cirad.fr
}

\section{Commission III, WG III/4}

KEY WORDS: Managed forest stand, wood energy, Very high spatial resolution, supervised classification, Random Forest, Vegetation index

\begin{abstract}
:
The development of a sustainable wood energy chain is an essential part of ecological and energy transition in Reunion Island (Indian Ocean), where Acacia mearnsii is the main potential wood energy resource identified to date. In order to assess future wood biomass supply chain strategies, a major first issue is to gain knowledge of the spatial distribution of this species forest stands.

In this study, we assessed the potential of very high spatial resolution multispectral imagery for mapping the main forest stands in a study area located the Western Highlands region, where Acacia mearnsii expands alongside Acacia heterophylla, an endemic forest species and Cryptomeria japonica, an exotic forest stand. A reference database including 150 samples of seven classes (Acacia mearnsii (mature and non-mature), Acacia heterophylla (mature and non-mature), Cryptomeria japonica, 'herbaceous areas', and 'bare soils') was used to classify a Pleiades image acquired in May 2020. Spectral and textural indices were used in an incremental classification procedure using a random classifier.

The best results (Kappa $=0.84$, global accuracy $=84 \%$ ) were obtained for the classification using all spectral and textural bands. The resulting map enables analyzing the spatial distribution of the different forest stands.
\end{abstract}

\section{INTRODUCTION}

Biomass is one of the main available sources of renewable energy that may contribute to the energy transition of a country or a region. However, the economic and environmental sustainability of bioenergy systems is highly dependent on reliable assessments of biomass resources availability and of supply chains. Assessing wood energy potential from managed forest stands may be particularly challenging in tropical environments.

In Reunion Island, a French overseas department located in Indian Ocean, Acacia mearnsii has been identified as the main potential resource for wood energy applications (ONF, 2018). This exotic species, introduced several decades ago, has expended to large areas of the territory due to its highly invasive dynamics. While control measures are still necessary to avoid further dissemination, future forest management plans expect to exploit this resource for wood energy but require additional assessments to refine its potential and the supply chain strategies. The main Acacia mearnsii stands

\footnotetext{
* Corresponding author
}

are located at rather high altitude, next to other managed forests stands, in particular to endemic Acacia heterophylla species, which belongs to the same Fabaceae family. However, these stands are heterogeneous in terms of structure, dendrometric characteristics, maturity and accessibility. Therefore, a major first issue is to gain knowledge of the spatial distribution of this species forest stands.

Remote sensing offers technologies for assessing and mapping the feedstock nature and quantity over large areas and at moderate costs. Kumar et al. have provided a comprehensive review of the techniques and methodologies used for these applications (Kumar et al., 2015). Forestry characteristics, such as tree crown or Diameter at breast height (DBH), can be estimated by Synthetic Aperture Radar (SAR) and Light Detection And Ranging (LiDAR) techniques. On the other hand, optical remote sensing has the advantage of covering large areas at low cost, with frequent image acquisition that enables updating the resulting maps. Moreover, forest stands discrimination gains in accuracy by using spectral and textural indices derived from high or very high spatial resolution imagery. 
In the present context, optical satellite remote sensing may be appropriate to provide updated high spatial resolution maps of the distribution of Acacia Mearnsii over Reunion Island and follow its dynamics.

Different studies based on optical remote sensing showed that supervised classification techniques gave satisficing results for mapping the invasive species Acacia mearnsii in Mediterranean (Paz-Kagan et al., 2019; Chekchaki et al., 2020) or subtropical (Piiroinen et al., 2017; Oumar et al., 2019; Masemola et al., 2020) environments. These studies highlighted the potential of optical imagery to map Acacia mearnsii stands based on vegetation indices (Oumar et al., 2019; Chekchaki et al., 2020; Piiroinen et al., 2017; Paz-Kagan et al., 2019). Vegetation characterization is also improved by the use of temporal series characterizing the vegetation phenology (Masemola et al., 2020).

In the present study, we explored the potential of very high spatial resolution multispectral imagery to locate Acacia mearnsii in Reunion Island. The challenge lies in determining the most relevant spectral and textural indices to discriminate this invasive forest stand from other forest stands using a supervised classification process.

\section{MATERIALS AND METHOD}

\subsection{Study area}

The study area was selected in the forests of the Western Highlands region of Reunion Island (Figure 1), where the major Acacia mearnsii stands are reported, with important biophysical diversity. The whole area extends over 4,300 ha located at altitudes ranging from 640 to $2,900 \mathrm{~m}$ above sea level and covers respectively $1,900 \mathrm{ha}$ and 2,400 ha of public and private areas for forestry or agricultural use. According to French National Forest Office (ONF) the forest public area comprises three main species, distributed in several stands. The most abundant species is endemic Acacia heterophylla, which represents more than half of the forest plots area. About $10 \%$ of the forest area is occupied by planted stands of exotic Cryptomeria japonica, managed for timber production. Finally, exotic and invasive Acacia mearnsii may occupy about $15-25 \%$ of the forest area.

The Acacia heterophylla stands were severely affected by several forest fires during last two decades, in particular in 2010-2011. On the one hand, these events benefitted to Acacia mearnsii expansion due to its pyrophilous properties (seeds activation by fire contact). On the other hand, reforesting campaigns were applied on several forest plots affected by fire, in order to relaunch endemic development in public lands.

\subsection{Data}

\subsubsection{Field reference data}

Fieldwork was organized with forest experts, in October 2020 and February 2021, in order to collect GPS coordinates of the main forest species in the study area. Regarding Acacia mearnsii and Acacia heterophylla, we refined our observations by noting the maturity of the forest stands. In order to collect GPS coordinates of nonforestry species occupations and Cryptomeria japonica, we used photo-interpretation of the Pleiades image (§2.2.2). Regarding data acquisition we considered seven classes: herbaceous areas, bare soils, Cryptomeria japonica, non-mature Acacia heterophylla, mature Acacia heterophylla, non-mature Acacia mearnsii, mature Acacia mearnsii.

The dataset was constituted of 175 samples and was divided into training (70\%) and validation (30\%) data.
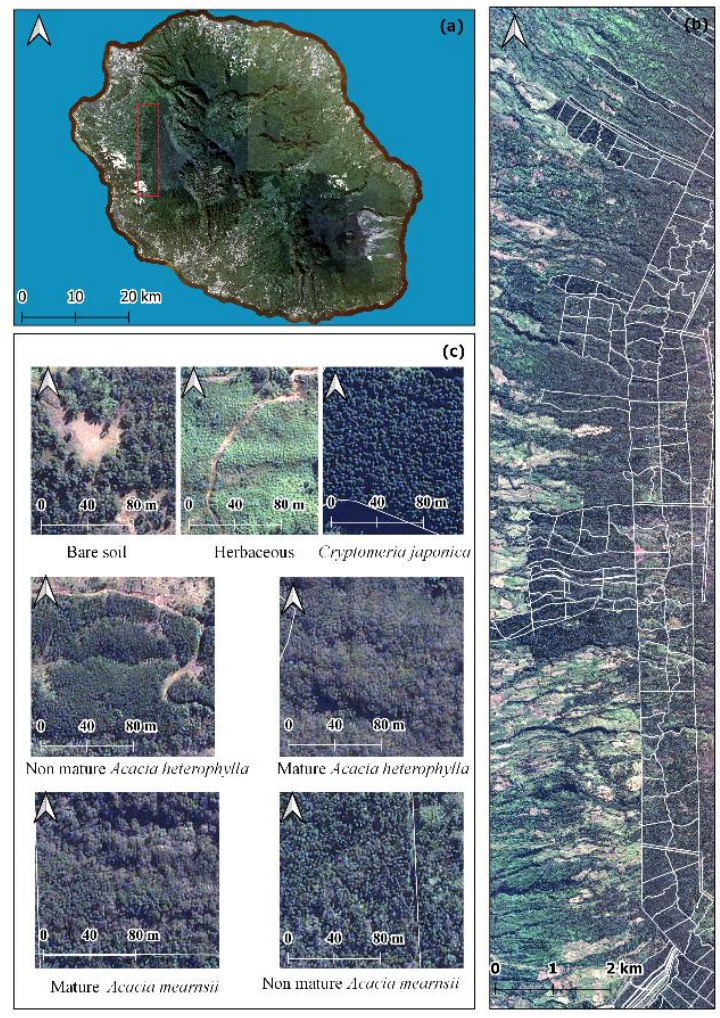

Figure 1. Study area, Western Highlands region, Reunion Island (a) Location of the study area (b) Pleiades image of the study area and delineation of public forest plots (in white) (c) Main land cover types and forest stands (C)

Pleiades Image Copyright 2018/2020, CNES.

\subsubsection{Remote sensing data}

Pleiades images are composed of five spectral bands, four of which cover the visible and near-infrared spectrum with a resolution of $2 \mathrm{~m}$, and one panchromatic band with a resolution of $50 \mathrm{~cm}$. We used an image from series $1 \mathrm{~A}$, acquired in May 2020, ortho-rectified in the UTM 40 projection system, and radiance-corrected into Top of Atmosphere reflectance values.

\subsection{Image pre-processing}

To increase the discrimination of forest stands, we extracted radiometric indices of vegetation and water from the pansharpened image of multispectral and panchromatic bands (Table 1). Using the Soil Adjusted 
Vegetation Index, we computed a mask covering water areas, roads and shades. Texture indices were also used to describe the image rugosity of forest patches. From the panchromatic band, we computed eight textural indices (energy, entropy, correlation, inverse difference moment, contrast, cluster shade, cluster prominence and Haralick correlation) derived from the grey-level scale matrix, as proposed by Haralick, 1973. As there is no consensus on the size of textural windows (Ferro, 2002), textural indices were computed on a sliding window of sizes ranging from $3 \times 3$ to $51 \times 51$ pixels, in order to determine which window size provides the most accuracy to the classification.

\begin{tabular}{|l|l|l|}
\hline Indice & Formule & Reference \\
\hline $\begin{array}{l}\text { NDVI }- \text { Normalized } \\
\text { Difference Vegetation } \\
\text { Index }\end{array}$ & (PIR-R)/(PIR+R) & Tucker, 1979 \\
\hline $\begin{array}{l}\text { NDWI2 - Normalized } \\
\text { Difference Water Index }\end{array}$ & (G-PIR)/(G+PIR) & $\begin{array}{l}\text { Mc Fleeters, } \\
1996\end{array}$ \\
\hline $\begin{array}{l}\text { SAVI - Soil Adjusted } \\
\text { Vegetation Index }\end{array}$ & (PIR-R/PIR+R+L)*1+L & Huete, 1988 \\
\hline $\begin{array}{l}\text { RGV - Red Green } \\
\text { Vegetation R/G }\end{array}$ & $\begin{array}{l}\text { Gamon \& al,, } \\
1999\end{array}$ \\
\hline $\begin{array}{l}\text { RVI - Ratio Vegetation } \\
\text { Index }\end{array}$ & PIR/R & $\begin{array}{l}\text { Krieger \& al., } \\
1979\end{array}$ \\
\hline
\end{tabular}

Table 1. Vegetation and water indices computed from Pleiades image.

\subsection{Input feature selection and classification}

From the training dataset, an incremental classification was performed using a random forest (RF) classifier with the R caret package (Breiman, 2001; Rodriguez-Galiano et al., 2012). The classifier was first applied to the textural indices in order to identify the window size with the best accuracy. Then, the corresponding textural indices $(n=8)$ were stacked with the multispectral bands $(\mathrm{n}=4)$ and radiometric indices $(\mathrm{n}=5)$. Given the high number of bands ( $\mathrm{n}=17$ ), we applied the Recursive Feature Selection (RFE) algorithm based on the RF classifier. The RFE algorithm aims at identifying the most important features for classification, by sequentially eliminating the less important feature for model prediction. At the end of the process, the features are ranked in order of importance. We used repeated k-cross validation, where $\mathrm{k}$ folds $=10$ and $\mathrm{r}$ repetition $=3$ in order to build a robust prediction model.

\subsection{Validation and post-treatments}

The accuracy of the classification obtained with the set of features identified through the RFE was assessed using the validation dataset. We use kappa index and the recall, giving information about producer and user accuracy.

Post classification with a $12 \times 12 \mathrm{~m}$ majority filter was applied to the resulting classification to remove noise.

\subsection{Forest stands cover evaluation and typology}

In order to evaluate the forest stands cover on public lands, the post-classification image was vectorized and superimposed on the public land layer in a Geographic Information System (GIS). The public forest plots (Figure 1) were classified according to National Geographic Institute definitions: a parcel was called "monospecific" if more than $75 \%$ of its surface was covered by a unique forest species, and "mixed" otherwise. Each plot was assigned to the dominant stand species.

\section{RESULTS}

\subsection{Texture analysis}

The evaluation of the classifications derived from textural indices calculated on windows of various sizes showed that the classification accuracy increases with texture window size (Figure 2). The best classification results were obtained for the texture window size of $51 \times 51$ pixels (Kappa index $=0.47$; overall accuracy $\mathrm{OA}=$ $56.1 \%)$.

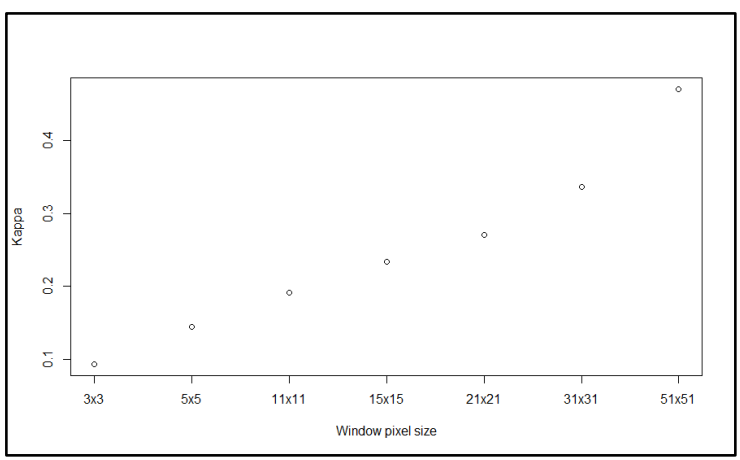

Figure 2. Comparison of classification accuracy based on texture windows sizes.

\subsection{Importance of input features}

The analysis of the RFE algorithm outputs showed an increase of the classification accuracy with the number of features, up to 17 features. RF classifier using the combination of all features performs significantly better $($ Kappa $=0.81, \mathrm{OA}=84.5 \%)$ than using only four features $($ Kappa $=0.73, \mathrm{OA}=77.9 \%)$.

The most important features identified by the RFE algorithm (vegetation index, followed by textural indices) are presented in Figure 3. The analysis of spectral and textural signatures showed that these indices largely contribute to discriminate forest stands. According to these results, the final classification was performed using all features.

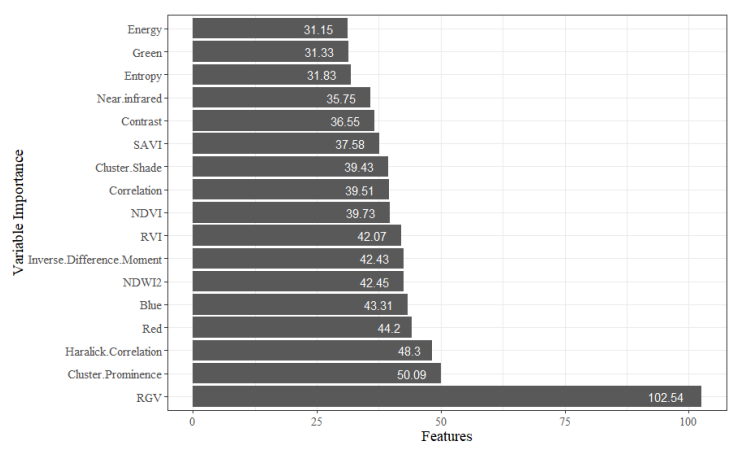

Figure 3. Features selected for classification, ranked by importance. 


\subsection{Assessment of the classification}

By using all features, the global accuracy classification reaches $84.4 \%$ and kappa index 0.84 (Table 2). The classes with the best producer accuracy are Bare soil (98.3\%), Herbaceous (97.1\%), Mature Acacia heterophylla $(89.9 \%)$, Cryptomeria japonica $(87.1 \%)$ and Non-mature Acacia heterophylla (75\%), while classes Acacia mearnsii obtain $71.2 \%$ for Mature Acacia mearnsii and $26.8 \%$ for Non-Mature Acacia mearnsii. Classes with best user accuracy are also Bare soil (99.5\%) and Herbaceous (98\%). This indicator is also better for classes of Non-mature Acacia heterophylla $(88.7 \%)$ and Cryptomeria japonica $(82.3 \%)$. Finally, it edges $71.9 \%$ for class of Mature Acacia heterophylla, $73.7 \%$ and $65.1 \%$ for classes of Non-mature Acacia mearnsii and Mature Acacia mearnsii. The confusion matrix (Table 2) indicates the discrimination capacity of the RF classifier for each class. Most of the confusions were observed between Acacia mearnsii and Acacia heterophylla classes. The resulting classification of the whole study area is presented in Figure 4.

\subsection{Evaluation and typology of forest stand cover}

The first results about forest stand evaluation shows that Acacia mearnsii was predominantly present in mixed forest stands on public forest plots (Figure 4). According to the classification results, monospecific plots either dominated by Cryptomeria japonica $(\mathrm{n}=11)$ or by Acacia heterophylla $(\mathrm{n}=18)$ were located in the western and northern parts of the study area, respectively.

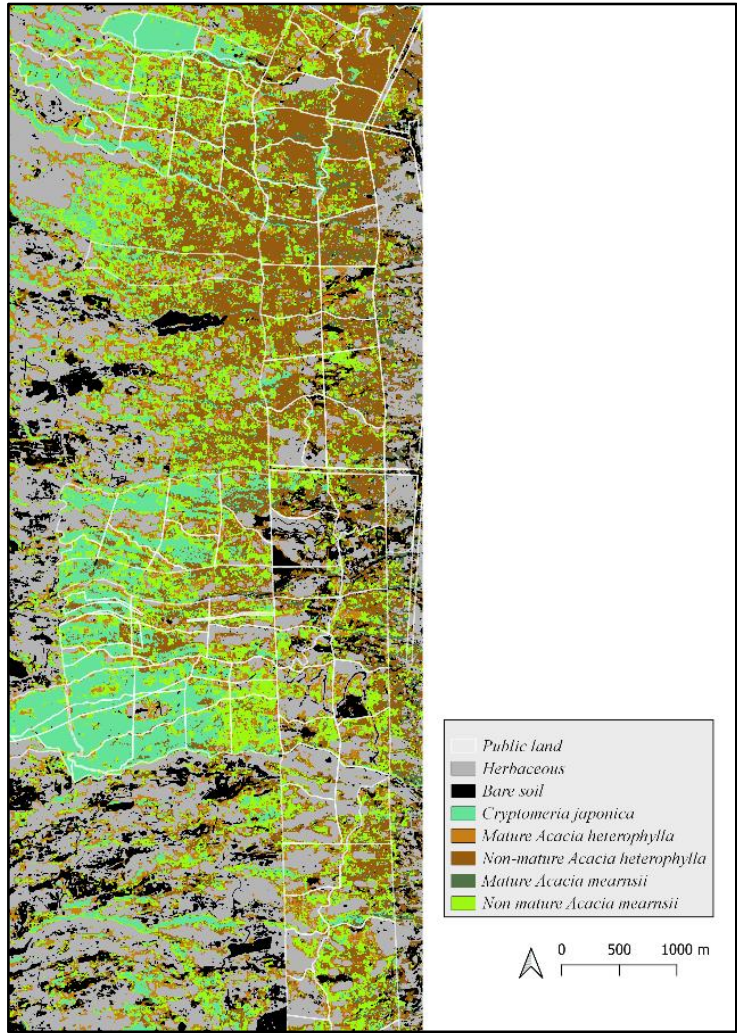

Figure 4. Map of forest species based on classification results, Western Highlands region, Reunion Island.

\begin{tabular}{|c|c|c|c|c|c|c|c|c|c|c|}
\hline & & \multicolumn{7}{|c|}{ REFERENCE } & \multirow[b]{2}{*}{ Total } & \multirow[b]{2}{*}{$\begin{array}{c}\text { User } \\
\text { accuracy }\end{array}$} \\
\hline & & Herb & $\begin{array}{c}\text { Bare } \\
\text { soil }\end{array}$ & $\begin{array}{l}\text { Cryp. } \\
\text { jap. }\end{array}$ & $\begin{array}{c}\text { Mature } \\
\text { Acacia } \\
\text { heterophylla }\end{array}$ & $\begin{array}{l}\text { Non-mature } \\
\text { Acacia } \\
\text { heterophylla }\end{array}$ & $\begin{array}{c}\text { Mature } \\
\text { Acacia } \\
\text { mearnsii }\end{array}$ & $\begin{array}{c}\text { Non- } \\
\text { mature } \\
\text { Acacia } \\
\text { mearnsii }\end{array}$ & & \\
\hline \multirow{9}{*}{$\underset{\sigma}{\infty}$} & Herb & 21470 & 47 & 8 & 99 & 35 & 186 & 70 & 21915 & 0.98 \\
\hline & Bare soil & 66 & 21865 & 0 & 23 & 0 & 22 & 1 & 21977 & 0.99 \\
\hline & $\begin{array}{c}\text { Cryptomeria } \\
\text { japonica }\end{array}$ & 6 & 115 & 19004 & 659 & 520 & 740 & 2058 & 23102 & 0.82 \\
\hline & $\begin{array}{c}\text { Mature Acacia } \\
\text { heterophylla }\end{array}$ & 305 & 136 & 1090 & 20160 & 136 & 3909 & 2287 & 28023 & 0.71 \\
\hline & $\begin{array}{l}\text { Non mature } \\
\text { Acacia } \\
\text { heterophylla }\end{array}$ & 43 & 0 & 98 & 10 & 4681 & 41 & 406 & 5279 & 0.88 \\
\hline & $\begin{array}{c}\text { Mature Acacia } \\
\text { mearnsii }\end{array}$ & 87 & 39 & 139 & 533 & 22 & 2245 & 379 & 3444 & 0.65 \\
\hline & $\begin{array}{c}\text { Non mature } \\
\text { Acacia mearnsii }\end{array}$ & 126 & 38 & 1458 & 919 & 824 & 1219 & 12872 & 17456 & 0.63 \\
\hline & Total & 22103 & 22240 & 21797 & 22403 & 6218 & 8362 & 18073 & 121196 & \\
\hline & $\begin{array}{l}\text { Producer } \\
\text { accuracy }\end{array}$ & 0.97 & 0.98 & 0.87 & 0.9 & 0.75 & 0.26 & 0.71 & & \\
\hline
\end{tabular}

Table 2. Confusion matrix and accuracy indicators 


\section{DISCUSSION}

The overall performance of the RF classifier was very good $(\mathrm{OA}=84 \%)$, confirming the performance of this algorithm for mapping land cover using optical remote sensing (Belgiu, 2016; Rodriguez-Galiano 2012). Regarding the discrimination of forest species, the overall performance of the RF classifier was satisfying, particularly for Cryptomeria japonica, whose spectral signature clearly differs from that of Acacia species. The classification accuracy was lower for Acacia mearnsii, although correct (recall $=26.8 \%$. user accuracy $=65.1 \%$ ). Of note, we obtained similar results than previous studies aiming at mapping Acacia species (e.g., Piiroinen et al., 2017).

The multispectral analysis showed that the radiometric signature of Acacia mearnsii is difficult to discriminate from that of mature Acacia heterophylla (Figure 5). To improve the classification of these two Acacia species, we therefore introduced textural indices in the classification, as the importance of texture indices was stressed for other forest species (Boukir et al., 2015; Lelong et al., 2020). Our results show that the use of these indices calculated on a large sliding window $(51 \times 51$ pixels) allows improving the discrimination of classes with low spectral separability. Tests for identifying the best texture window size require large computation time, but our results stressed how forest species classification can be improved by using the appropriate textural window size.

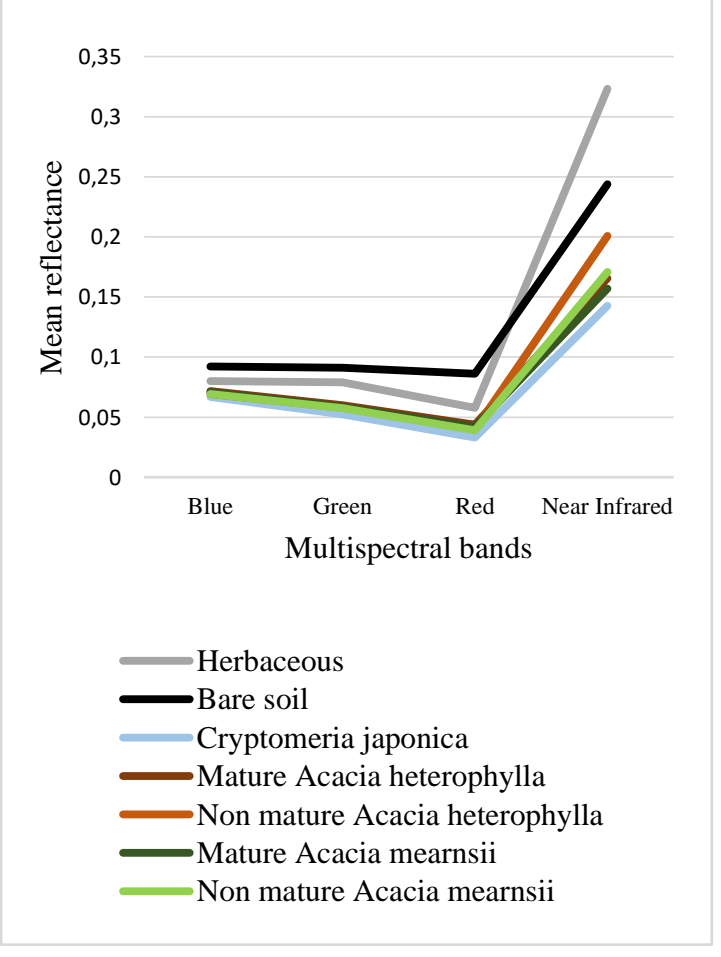

Figure 5. Multispectral signatures

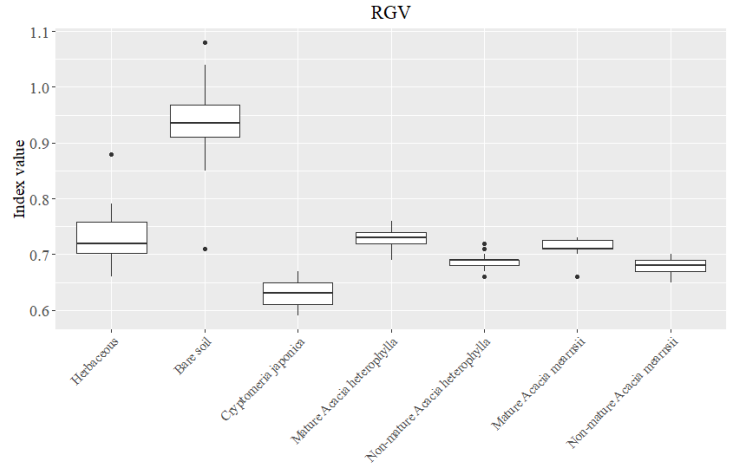

Figure 6. Values of the best spectral index (RGV) as selected by the RFE algorithm for different land cover types, Western Highland Region, Reunion Island.

The results of the RFE algorithm confirmed the importance of textural indices, in combination with a vegetation index, for optimizing the classification accuracy (Figure 3; Figure 6). Other indices, such as the near-infrared reflectance, were important features to improve discrimination between Acacia mearnsii and Acacia heterophylla (mature and non-mature stands). Therefore, all features were included in the classification process, as in our case, the number of features could not be reduced without strongly reducing the classification accuracy, unlike other research studies (Shi, 2016; Nguimdo, 2020).

\section{CONCLUSION}

The overall performance of the RF classifier applied on a very high spatial resolution image was very good, allowing mapping the different forest stands in our study area. Including textural indices combined with vegetation indices in the classification process significantly improved discrimination between forest species, in particularly for Cryptomeria japonica, Non-Mature Acacia heterophylla and Mature Acacia mearnsii, whose spectral signatures clearly differ from other forest species. Combining the remote sensing derived classification with GIS functionalities provided a first illustration on the use of satellite-derived information to quantify and qualify forest stands over the study area. This information will contribute to the spatial modelling of the wood energy chain in Reunion Island. Research perspectives include the comparison with the classification results obtained with Earth Observation image acquired at a lower spatial resolution (e.g Spot 6/7, Sentinel-2) but covering larger areas. The main issue will consist in looking for a compromise between spatial accuracy and spatial extent. In the future, the repeatability of multispectral image acquisitions will allow monitoring of forested resources over Reunion Island by updating the map used for the developed method. 


\section{AKNOWLEDGEMENTS}

This work benefited from the Pleiades images of the Kalideos program funded by CNES.

We would like to thank the National Forestry Office (ONF) and teams of Cirad units (TETIS, BioWooEB) for sharing their data and participating in the creation of the training database.

We also thank the Conseil Départemental de La Réunion, the Conseil Régional de La Réunion, the French ministry of agriculture and food, the European Union (Feader program, grant $\mathrm{n}^{\circ} \mathrm{AG} / 974 / \mathrm{DAAF} / 2016-00096$, and Feder program, grant $\mathrm{n}^{\circ}$ GURTDI 20151501-0000735), and Cirad for funding the present work within the framework of the project 'Services et impacts des activités agricoles en milieu tropical' (Siaam).

\section{REFERENCES}

Belgiu, M., Drăguţ, L., 2016. Random forest in remote sensing: A review of applications and future directions. ISPRS Journal of Photogrammetry and Remote Sensing 114 , 24-31. https://doi.org/10.1016/j.isprsjprs.2016.01.011

Boukir, S., Regniers, O., Guo, L., Bombrun, L., Germain, C., 2015. texture-based forest cover classification using random forests and ensemble margin, in: IEEE International Geoscience and Remote Sensing Symposium 2015. Milan, Italy, pp. 3072-3075.

Breiman, L., 2001. Random forests. Machine Learning 45 (1), 5-32.

Chekchaki, S., Beddiar, A., Zaafour, M., 2020. Cartographie par télédétection des milieux envahis par Acacia mearnsii De Wild. dans l'extrême Nord-Est algérien. BOIS \& FORETS DES TROPIQUES 343, 516. https://doi.org/10.19182/bft2020.343.a31835

Ferro, C., Warner, T., 2002. Scale and Texture in Digital lmage Classification. Photogrammetric Engineering and Remote Sensing 68, 51-63.

Gamon, J.A., Surfus, J.S., 1999. Assessing leaf pigment content and activity with a reflectometer. New Phytologist 143, 105-117. https://doi.org/10.1046/j.14698137.1999.00424.x

Huete, A.R., 1988. A soil-adjusted vegetation index (SAVI). Remote Sensing of Environment 25, 295-309. https://doi.org/10.1016/0034-4257(88)90106-X

Krieger, F., Malila, W., Nalepka, R., Richerdson, W., 1969. Preprocessing transformations and their effects on multispectral recognition. (Proc. Of the 6th Int. Symp. on Remote Sensing of Environment. University of Michigan, Ann Arbor) 97-131

Kumar, L., Sinha, P., Taylor, S., Alqurashi, A.F., 2015. Review of the use of remote sensing for biomass estimation to support renewable energy generation. JARS 9, 097696. https://doi.org/10.1117/1.JRS.9.097696

Lelong, C.C.D., Tshingomba, U.K., Soti, V., 2020. Assessing Worldview-3 multispectral imaging abilities to map the tree diversity in semi-arid parklands. International Journal of Applied Earth Observation and Geoinformation $93,102211$. https://doi.org/10.1016/j.jag.2020.102211

Masemola, C., Cho, M.A., Ramoelo, A., 2020. Sentinel-2 time series based optimal features and time window for mapping invasive Australian native Acacia species in KwaZulu Natal, South Africa. International Journal of Applied Earth Observation and Geoinformation 93, 102207. https://doi.org/10.1016/j.jag.2020.102207

McFeeters, S. K., 1996. The use of the normalised difference water index (NDWI) in the delineation of open water features. International Journal of Remote Sensing 17, 1425-1432.

Nguimdo, C.A.M., Tiomo, E.D., 2020. Foret d'arbres aleatoires et classification d'images satellites: relation entre la precision du modele d'entrainement et la precision globale de la classification. RFPT 3-14.

Oumar, M., Peerbhay, K., Germishuizen, I., Mutanga, O., Oumar, Z., 2019. Detecting canopy damage caused by Uromycladium acaciae on South African Black Wattle forest compartments using moderate resolution satellite imagery. https://doi.org/10.4314/sajg.v8i1.5

Paz-Kagan, T., Silver, M., Panov, N., Karnieli, A., 2019. Multispectral Approach for Identifying Invasive Plant Species Based on Flowering Phenology Characteristics. Remote Sensing 11, 953. https://doi.org/10.3390/rs11080953

Piiroinen, R., Heiskanen, J., Maeda, E., Viinikka, A., Pellikka, P., 2017. Classification of Tree Species in a Diverse African Agroforestry Landscape Using Imaging Spectroscopy and Laser Scanning. Remote Sensing 9, 875. https://doi.org/10.3390/rs9090875

Rodriguez-Galiano, V.F., Ghimire, B., Rogan, J., ChicaOlmo, M., Rigol-Sanchez, J.P., 2012. An assessment of the effectiveness of a random forest classifier for landcover classification. ISPRS Journal of Photogrammetry and Remote Sensing 67, 93-104. https://doi.org/10.1016/j.isprsjprs.2011.11.002

Shi, D., Yang, X., 2016. An Assessment of Algorithmic Parameters Affecting Image Classification Accuracy by Random Forests. Photogram Engng Rem Sens 82, 407417. https://doi.org/10.14358/PERS.82.6.407

Tucker, C.J., 1979. Red and photographic infrared linear combinations for monitoring vegetation. Remote Sensing of Environment 8, 127-150. https://doi.org/10.1016/0034-4257(79)90013-0 